\title{
Relação entre condutividade elétrica e desempenho fisiológico de sementes de arroz
}

\author{
Carla Aparecida ASCOLI ${ }^{1 *}$, Andréa Carvalho da Silva ${ }^{1}$ \\ ${ }^{1}$ Programa de Pós-Graduação em Agronomia, Universidade Federal de Mato Grosso, Sinop, MT, Brasil. \\ *E-mail: ascolicarla@gmail.com \\ (Orcid: 0000-0002-1929-5430; 0000-0003-2921-3379)
}

Recebido em 09/06/2020; Aceito em 17/05/2021; Publicado em 06/06/2021.

\begin{abstract}
RESUMO: Estudando genótipos de arroz (Oryza sativa L.), ANa 8001, 9005 CL e 9027, determinou-se o potencial fisiológico das sementes, sendo o mesmo correlacionado com índices de condutividade elétrica. $\mathrm{O}$ experimento foi conduzido nas safras 2017/18 em Sinop-MT, na determinação dos índices de condutividade elétrica foram avaliados dois fatores de luminosidade e 9 períodos de embebição. Adotou-se o delineamento inteiramente casualizado com comparação de médias pelo Teste de Tukey (5\%), quando necessário, os dados foram transformados por raiz quadrada. Os resultados destacaram a cultivar $\mathrm{ANa} 9027 \mathrm{com}$ o pior desempenho fisiológico, vigor de 69\%, e para as demais cultivares ANa 8001 (79,54\%) e ANa 9005 CL (84,41\%). O teor de água absorvido pelas sementes do início do processo de hidratação até o final, é afetada pela qualidade fisiológica, sementes menos vigorosas apresentam menor velocidade de hidratação e umidade final. Constatouse também, que o teste de condutividade elétrica é eficiente para determinar a viabilidade de sementes de arroz e a melhor resposta foi obtida na ausência de luz, além disso é possível a redução do período de imersão para $8 \mathrm{~h}$ com o intuito de diferenciar o potencial fisiológico das sementes de arroz acima de $80 \%$ de vigor, daquelas abaixo desse padrão.
\end{abstract}

Palavras-chave: qualidade fisiológica; Oryza sativa; vigor de sementes; germinação.

\section{Relationship between electrical conductivity and physiological performance of rice seeds}

\begin{abstract}
Studying genotypes of rice (Oryza sativa L.), ANa 8001, 9005 CL and 9027, the physiological potential of the seeds was determined, being the same correlated with electrical conductivity indices. The experiment was conducted in the 2017/18 harvests in Sinop-MT, in determining the electrical conductivity indices, two luminosity factors and 9 imbibition periods were evaluated. It was adopted a completely randomized design with comparison of means by the Tukey test $(5 \%)$, when necessary, the data were transformed by square root. The results highlighted the cultivar ANa 9027 with the worst physiological performance, 69\% vigor, and for the other cultivars $\mathrm{ANa} 8001$ (79.54\%) and $\mathrm{ANa} 9005 \mathrm{CL}$ (84.41\%). The water content absorbed by the seeds from the beginning of the hydration process to the end, is affected by the physiological quality, less vigorous seeds have a lower rate of hydration and final moisture. It was also found that the electrical conductivity test is efficient to determine the viability of rice seeds and the best response was obtained in the absence of light, in addition it is possible to reduce the immersion period to $8 \mathrm{~h}$ in order to differentiate the physiological potential of rice seeds above $80 \%$ vigor, those below this standard.
\end{abstract}

Keywords: physiological quality; Oryza sativa; seed vigor; germination.

\section{INTRODUÇÃO}

Os dados mais recentes divulgados pela Associação Brasileira de Sementes e Mudas (ABRASEM), são de 2018 e mostram que a produção de sementes de arroz no Brasil ficou em torno de 179.451 toneladas na safra 2017/18, com uma taxa de utilização na safra 2016/2017 de 56\% (ABRASEM, 2018), apesar dos avanços tecnológicos e inovações na produção de sementes de arroz.

Esses avanços tecnológicos beneficiam toda a cadeia produtiva, melhoram a adaptabilidade a condições adversas, qualidades nutricionais, controle de plantas daninhas, até melhores características de transporte e durabilidade póscolheita, através do melhoramento genético, irrigação, manejo da cultura, entre outros fatores.

Quando não se faz uso de sementes certificadas, destacam-se como principais prejuízos, além das perdas de produtividade, perdas econômicas para o mercado de sementes. Os obtentores investem aproximadamente 10\% das vendas totais das empresas, anualmente, em pesquisa e desenvolvimento gerando inovações na área de sementes (ABRASEM, 2018), além das perdas de mercado interno e externo

Por outro lado, o uso de sementes certificadas, segundo Cantarelli et al. (2015), é garantia de boa qualidade e alto potencial fisiológico, além de boa qualidade sanitária.

A boa qualidade fisiológica garantida por sementes certificadas leva ao aumento da produtividade, que é ocasionado pelo crescimento inicial uniforme e estabelecimento de população adequada.

Esse fato ocorre porque o estabelecimento inicial de uma lavoura depende essencialmente do potencial fisiológico das sementes utilizadas na semeadura. A porcentagem, 
velocidade e uniformidade de emergência de plântulas dependem desse potencial. Sementes de alta qualidade resultam em plântulas fortes, vigorosas, bem desenvolvidas e que se estabelecem nas diferentes condições edafoclimáticas, com maior velocidade de emergência e de desenvolvimento (FRANÇA NETO et al., 2010).

Como consequência da alta qualidade e da velocidade de emergência, as plântulas resultantes apresentam alto desempenho agronômico, com melhor estrutura de parte aérea e com um sistema radicular mais profundo e robusto (FRANÇA NETO; KRZYZANOWSKI, 2018). Apresentam também menor necessidade de ressemeadura.

Além disso, plantas de alto desempenho aproveitam de maneira mais eficiente os recursos disponíveis para o seu desenvolvimento, como água, luz (fotossíntese), nutrientes e devido ao seu rápido desenvolvimento no campo reduzem a mato competição, a lavoura terá menores problemas com incidência de plantas daninhas e menor necessidade de herbicidas (FRANÇA NETO; KRZYZANOWSKI, 2018).

Esses fatores dentre outros garante uma lavoura com maior desempenho e consequentemente, apresentam um potencial produtivo maior.

A qualidade de sementes pode ser definida como um conjunto de características que estabelecem o valor de um lote de determinada cultivar para a semeadura (MARCOS FILHO, 2015), indicando que a qualidade só pode ser identificada, de forma consistente, quando se considera a interação entre os atributos físicos, genéticos, fisiológicos e sanitários e que só pode ser comprovada através de análises.

A análise de sementes é um grupo de procedimentos técnicos utilizados para avaliar a qualidade e a identidade da amostra e para essa avaliação são empregadas metodologias padronizadas, tanto para os testes físicos quanto para os testes que determinam a qualidade fisiológica em si. A junção dos resultados obtidos nesses procedimentos, indica o parâmetro geral de qualidade das sementes (BRASIL, 2003).

Os testes fisiológicos determinam a atividade fisiológica específica e assim a "qualidade" e dentro da qualidade fisiológica são abordados os conceitos de vigor, germinação e viabilidade.

O vigor é um conceito de desempenho fisiológico que pode ser traduzido como, aquelas propriedades das sementes que determinam o seu potencial para uma emergência rápida e uniforme e o desenvolvimento de plântulas normais sob ampla diversidade de condições de ambiente (AOSA, 1983; RAJJOU et al., 2012).

A germinação corresponde ao conjunto de processos associados com a fase inicial do desenvolvimento da estrutura da planta, que iniciam pela absorção de água e, na maioria das vezes, termina com a emissão da radícula.

O teste de germinação tem por objetivo determinar o máximo potencial germinativo de um lote de sementes, já a viabilidade de um lote de sementes é expressa em termos de percentagem de sementes vivas capazes de germinar (FRANDOLOSO, 2016).

Os testes que têm por base o vigor e a germinação da semente, como o de primeira contagem, teste padrão de germinação e emergência em areia, estão fundamentados na atividade metabólica das sementes, que é a sua capacidade de metabolizar e transportar os tecidos de reservas presentes, como carboidratos, lipídios e proteínas nos cotilédones para o eixo embrionário, para a formação da nova plântula (FRANÇA NETO; KRZYZANOWSKI, 2018). Esses testes são consagrados pela sua ampla aplicação e confiabilidade dos resultados obtidos, porém pode-se ressaltar uma limitação devido ao tempo demandado na obtenção dos resultados.

A utilização de métodos rápidos, confiáveis e de fácil execução é fundamental para a avaliação do potencial fisiológico das sementes, por agilizar as tomadas de decisões referentes ao manejo dos lotes (MERTZ et al., 2012), nesse sentido o teste de condutividade elétrica é uma alternativa.

$\mathrm{O}$ teste de condutividade elétrica baseia-se no princípio de que sementes mais deterioradas liberam maiores quantidades de solutos para a solução, os solutos liberados possuem propriedades eletrolíticas capazes de conduzir corrente elétrica que é medida por um condutivímetro (MARCOS FILHO, 2015).

Como a deterioração das sementes inicia pela degradação do sistema de membranas, métodos que avaliam esta degradação são os mais indicados para diferenciar lotes com pequenas diferenças de vigor, detectando o processo de deterioração em sua fase inicial (MARQUES et al., 2014).

Para tanto objetivou-se determinar o potencial fisiológico das sementes de três genótipos de arroz por meio de diferentes testes de vigor, germinação e viabilidade e correlacionar com os índices de condutividade elétrica, além, de comprovar a eficiência de uma metodologia alternativa, com redução do tempo de embebição para o teste de condutividade elétrica.

\section{MATERIAL E MÉTODOS}

O experimento foi conduzido na safra de cultivo dos anos 2017/2018, nos períodos compreendidos entre os meses de outubro a março, na região de transição Cerrado-Amazônia, na empresa Agro Norte Pesquisa e Sementes (ANPS) localizada em de Sinop/MT $\left(11,42^{\circ} \mathrm{S} ; 55,27^{\circ} \mathrm{W}\right)$.

Foram selecionados aleatoriamente 9 lotes $(3$ lotes de cada cultivar) de sementes de arroz de sequeiro das cultivares ANa 8001, ANa 9005 CL e ANa 9027, produzidos na safra $2017 / 2018$. Os campos de produção estão localizados no município de Nova Santa Helena-MT. A cultivar ANa 8001 foi plantada nas coordenadas $10,56^{\circ} \mathrm{S}$ e $55,03^{\circ} \mathrm{W}$, com data de plantio em 16/12/17 e data de colheita em 07/04/2018 (Ciclo de 112 dias) e as cultivares ANa 9005 CL e ANa 9027 foram plantadas nas coordenadas $11,44^{\circ} \mathrm{S}$ e $55,31^{\circ} \mathrm{W}$, com data de plantio em 11/11/17 e data de colheita em 06/03/2018 (Ciclo para ambas de 115 dias).

O solo da área é do tipo Latossolo Vermelho Amarelo Distrófico, de classe textural argilosa. Segundo a classificação de Koppen, o tipo climático predominante na região é o Aw (clima tropical úmido), com estação seca bem definida, com precipitação média anual em torno de $1.940 \mathrm{~mm}$, sendo que $85 \%$ desse total se concentram no período de outubro a março (SOUZA et al., 2013).

As amostras de sementes de todos os genótipos usadas em todo o experimento foram armazenadas em câmara fria $\left(15{ }^{\circ} \mathrm{C}\right.$ e $40 \%$ UR), no Laboratório de Análise de Sementes (ANPS), do mês de maio de 2018 até a condução total do experimento, sendo realizadas as seguintes determinações:

\subsection{Umidade ou teor de água (U)}

A determinação da umidade das sementes foi realizada em uma estufa com circulação forçada de ar regulada a temperatura de $105 \pm 3{ }^{\circ} \mathrm{C}$ por $24 \mathrm{~h}$. Foram utilizadas quatro subamostras de $5 \mathrm{~g}$ de sementes para cada lote, pesadas em balança analítica com resolução de $0,0001 \mathrm{~g}$, baseando-se nas 
recomendações da Regra de análises de sementes (BRASIL, 2009), com alterações, determinando-se a porcentagem de umidade em base úmida.

\subsection{Teste padrão de germinação e primeira contagem do teste padrão de germinação}

O teste padrão de germinação foi conduzido com 400sementes para cada lote (4 repetições de 100 sementes), sendo a semeadura realizada entre papel germitest umedecido com água destilada ( $\mathrm{pH}$ ) na proporção de 2,5 vezes a massa do papel seco. Após a semeadura foram confeccionados rolos, os quais permaneceram em germinador tipo BOD sob luz com fotoperíodo de $8 \mathrm{~h}$ e temperatura constante de $25 \pm$ $1{ }^{\circ} \mathrm{C}$.

A avaliação de germinação foi realizada no $14^{\circ}$ dia após a semeadura, computando-se a porcentagem de plântulas normais, conforme Brasil (2009). Foram consideradas plântulas normais àquelas que alcançaram o estádio em que todas as estruturas essenciais podem ser precisamente verificadas, para a semente do arroz consideram-se as estruturas morfológicas: presença da raiz primária e parte aérea bem desenvolvida.

A primeira contagem do teste padrão de germinação foi realizada conjuntamente com o teste de germinação, onde foi determinada a porcentagem de plântulas normais ao sétimo dia após a instalação do experimento (BRASIL, 2009).

Foi considerado nesse caso apenas as plântulas normais que apresentam raiz primária, partes aéreas bem desenvolvidas e raízes secundárias. $\mathrm{O}$ número de plântulas normais removidas na primeira contagem é o indicativo do vigor do lote de sementes.

\subsection{Emergência em areia}

O teste de emergência em areia foi conduzido com o uso de bandejas de plástico com $10 \mathrm{~cm}$ de profundidade. Quatro repetições de 100 sementes por lote foram semeadas a $3 \mathrm{~cm}$ de profundidade entre areia fina lavada, permanecendo em germinador tipo BOD sob luz com fotoperíodo de $8 \mathrm{~h}$ e temperatura constante de $25 \pm 1{ }^{\circ} \mathrm{C}$.

O volume de areia utilizado foi umedecido com água a $50 \%$ de sua capacidade de campo e umedecidos novamente sempre que necessário. Contabilizando-se as plântulas emergidas aos 7 e 14 dias após a semeadura.

\subsection{Tetrazólio}

Foram descascadas cerca de 130 sementes em quatro repetições para cada lote, em descascador para arroz, marca ZACCARIA, modelo PAZ 1-DT, utilizou-se trinta por cento a mais de sementes como uma medida de segurança pela ocorrência de sementes que deixaram de ser descascadas e aquelas que apresentavam algum dano na região do embrião, além da margem de segurança para eventuais erros na preparação (corte).

Para a realização das avaliações foram utilizadas 100 sementes inteiras, divididas em duas subamostras de 50 sementes para cada repetição de cada lote. As sementes foram submetidas ao pré-umedecimento mediante imersão em $20 \mathrm{~mL}$ de água e mantidos à temperatura de $20^{\circ} \mathrm{C}$ durante 18 h (BRASIL, 2009).

Decorrido esse período, as sementes foram separadas da água e em seguida foi realizado corte longitudinal no centro do embrião, com auxílio de uma lâmina, retirando e descartando $1 / 2$ da largura da semente. Após esta etapa as sementes foram submersas em solução $1 \%$ de cloreto $2,3,5$ - trifenil tetrazólio por duas horas, permanecendo no escuro a $35{ }^{\circ} \mathrm{C}$, conforme recomendação da regra de análise de sementes (BRASIL, 2009).

Após o período de coloração, as sementes foram lavadas em água corrente e avaliadas individualmente, observando-se a coloração do embrião, sendo classificadas em viáveis e não viáveis de acordo com a coloração apresentada no eixo embrionário, computando-se a porcentagem de sementes viáveis.

\subsection{Curvas de embebição (CE)}

As curvas de embebição foram obtidas colocando-se 4 repetições de 100 sementes por lote entre papel umedecido $\operatorname{com} 2,5$ vezes o seu peso e mantidas a $25^{\circ} \mathrm{C}$.

As sementes foram pesadas inicialmente $(0 \mathrm{~h})$ e em períodos pré-definidos $(2,4,6,8,10,12,24,36,48,60$ e 72 h) até se observar o início da emergência da raiz primária.

\subsection{Condutividade elétrica da solução com exsudatos das sementes}

Para todos os genótipos utilizaram-se oito repetições (50 sementes) para cada lote, cada repetição foi pesada e colocada em copos de plástico $(200 \mathrm{~mL})$, contendo $75 \mathrm{~mL}$ de água deionizada, sob a temperatura de $25 \pm 1{ }^{\circ} \mathrm{C}$. Separou-se 4 repetições que foram mantidas pelo tempo de embebição na ausência de luz e outras 4 repetições mantidas sob fotoperíodo de $8 \mathrm{~h}$. Avaliou-se os períodos de embebição de $4,8,12,16,20,24,32,40$ e $48 \mathrm{~h}$.

Após decorrido cada período de embebição, procedeu-se as leituras de condutividade elétrica com um condutivímetro de bancada, microprocessado com compensação automática de temperatura, Modelo 30107-03, marca ASTRAL Científica, calibrado em solução de condutividade padrão com condutividade de $1413 \mu \mathrm{S} \mathrm{cm} \mathrm{cm}^{-1}$.

Os valores obtidos foram divididos pelas respectivas massas das sementes, calculada a média e expressos em $\mu \mathrm{S}$ $\mathrm{cm}^{-1} \mathrm{~g}^{-1}$ (KRZYZANOWSKI et al., 1999).

\subsection{Análise estatística}

O experimento foi conduzido segundo o delineamento inteiramente casualizado para todas as avaliações realizadas e a normalidade dos dados foi verificada pelo teste de ShapiroWilk para Normalidade ao nível de significância de $5 \%$.

Os dados que não seguiram a distribuição normal foram submetidos a transformação pela raiz quadrada, que é indicada para dados obtidos por processo de contagem (Equação 1).

$$
X=\sqrt{\frac{x}{100}}
$$

em que: $\mathrm{X}=$ dado transformado; $\mathrm{x}=$ dado lido.

As médias submetidas à análise de variância - ANOVA, constatando-se diferença estatística, foram comparadas pelo Teste de Tukey, a 5\% de significância. A ANOVA bem como o teste de comparação de médias - Teste de Tukey e o teste de Shapiro-Wilk para Normalidade foi ajustado pelo pacote estatístico Sisvar, versão 5.6, Build 86.

\section{RESULTADOS}

Entre os lotes de uma mesma cultivar houve variação significativa nas porcentagens de umidade, assim como entre as diferentes cultivares (Tabela 1). 
Tabela 1. Umidade (porcentagem em base úmida) das cultivares de arroz ANa 8001, ANa 9005 CL e ANa 9027, 45 dias após o armazenamento em condições refrigeradas.

Table 1. Moisture (percentage on wet basis) of rice cultivars ANa 8001, ANa 9005 CL and ANa 9027, 45 days after storage under refrigerated conditions.

\begin{tabular}{lllll}
\hline \multicolumn{5}{c}{ Umidade $(\%)$} \\
\hline Lote 1 & Lote 2 & Lote 3 & Média \\
\hline ANa 8001 & $11,44 \mathrm{Aa}$ & $11,83 \mathrm{Bb}$ & $11,86 \mathrm{Bb}$ & $11,71 \mathrm{~B}$ \\
ANa 9005 CL & $11,63 \mathrm{Ba}$ & $11,48 \mathrm{Aa}$ & $11,53 \mathrm{Aa}$ & $11,55 \mathrm{AB}$ \\
ANa 9027 & $11,26 \mathrm{Aa}$ & $11,73 \mathrm{Bb}$ & $11,41 \mathrm{Aa}$ & $11,47 \mathrm{~A}$ \\
\hline Média & $11,44 \mathrm{a}$ & $11,60 \mathrm{~b}$ & $11,68 \mathrm{~b}$ & \\
\hline
\end{tabular}

Médias seguidas por uma mesma letra, maiúscula na coluna e minúscula na linha, não diferem estatisticamente (Tukey, p > 0,05).

De forma geral, nas médias finais dos lotes, observa-se que a cultivar $\mathrm{ANa} 8001$ apresentou umidade superior a cultivar $\mathrm{ANa} 9027$ em $0,24 \%$ e estatisticamente igual a cultivar $\mathrm{ANa}$ 8001. Ressalta-se que os dados obtidos para o teor de água das sementes são semelhantes para os 9 lotes, com variação de até 0,45 pontos percentuais.

Nos testes diretos de avaliação do vigor e germinação, observa-se o mesmo padrão de comportamento para as 3 cultivares e os 3 lotes dentro da mesma cultivar. Para o teste de primeira contagem da germinação (PCG) (Tabela 2), considerou-se as plântulas normais fortes contabilizadas no $7^{\circ}$ dia da semeadura refletindo o índice de vigor.

Tabela 2. Teste da primeira contagem da germinação e teste padrão de germinação das sementes das cultivares de arroz $\mathrm{ANa} 8001, \mathrm{ANa}$ 9005 CL e ANa 9027.

Table 2. First germination count test and seed germination pattern of rice cultivars $\mathrm{ANa} 8001, \mathrm{ANa} 9005 \mathrm{CL}$ and $\mathrm{ANa} 9027$.

\begin{tabular}{|c|c|c|c|c|}
\hline \multicolumn{5}{|c|}{ Primeira contagem da germinação (PCG) } \\
\hline & Lote 1 & Lote 2 & Lote 3 & Média \\
\hline ANa 8001 & $79,75 \mathrm{Ba}$ & $79,00 \mathrm{Ba}$ & $76,25 \mathrm{Ba}$ & $78,33 \mathrm{~B}$ \\
\hline $\mathrm{ANa} 9005 \mathrm{CL}$ & $86,00 \mathrm{Ca}$ & $86,25 \mathrm{Ca}$ & $82,50 \mathrm{Ca}$ & $84,91 \mathrm{C}$ \\
\hline ANa 9027 & $71,00 \mathrm{Aa}$ & $71,25 \mathrm{Aa}$ & $70,25 \mathrm{Aa}$ & $70,83 \mathrm{~A}$ \\
\hline Média & $78,91 \mathrm{a}$ & $78,83 \mathrm{a}$ & $76,33 \mathrm{a}$ & \\
\hline \multicolumn{5}{|c|}{ Teste padrão de germinação (SCG) } \\
\hline $\mathrm{ANa} 8001$ & $87,75 \mathrm{Ba}$ & $87,00 \mathrm{Aa}$ & $89,75 \mathrm{Ba}$ & $88,16 \mathrm{~B}$ \\
\hline $\mathrm{ANa} 9005 \mathrm{CL}$ & $93,25 \mathrm{Ca}$ & $93,25 \mathrm{Ba}$ & $95,50 \mathrm{Ca}$ & $94,00 \mathrm{C}$ \\
\hline ANa 9027 & $81,25 \mathrm{Aa}$ & $83,75 \mathrm{Aa}$ & $80,50 \mathrm{Aa}$ & $81,83 \mathrm{~A}$ \\
\hline Média & $87,41 \mathrm{a}$ & $88,00 \mathrm{a}$ & $88,58 \mathrm{a}$ & \\
\hline
\end{tabular}

Médias seguidas por uma mesma letra, maiúscula na coluna e minúscula na linha, não diferem estatisticamente (Tukey, $\mathrm{p}>0,05)$.

A cultivar ANa 9005 CL apresentou os maiores índices de vigor, evidenciando uma qualidade superior quando comparada as demais cultivares e dentro dos padrões mínimos exigidos pelo MAPA $(80 \%)$.

O menor índice de vigor foi registrado para a cultivar ANa 9027, já a cultivar ANa 8001 apresentou um padrão de vigor intermediário, índices acima da cultivar ANa 9027, e abaixo da cultivar ANa 9005 CL.

Nos percentuais de germinação dados através do teste padrão de germinação (Tabela 2), segunda contagem realizada ao $14^{\circ}$ dia da semeadura, (SCG), constatou-se diferenças significativas para os índices de germinação das cultivares, não sendo observadas diferenças quando considerados os lotes dentro da mesma cultivar.

A cultivar ANa 9005 CL se destacou pelo maior índice de germinação, seguido pela cultivar $\mathrm{ANa}$ 8001. A cultivar $\mathrm{ANa}$ 9027 apresentou o menor índice de germinação, seguindo o padrão estabelecido pelo vigor na primeira contagem da germinação.
No teste de emergência em areia (Tabela 3), verifica-se na primeira contagem da emergência em areia ao $7^{\circ}$ dia, que a cultivar ANa 9027 apresentou o menor percentual de plântulas viáveis sendo a de menor índice de vigor em relação as demais.

Tabela 3. Emergência em areia de sementes das cultivares de arroz ANa 8001, ANa 9005 CL e ANa 9027.

Table 3. Emergence in seed sand of rice cultivars $\mathrm{ANa} 8001, \mathrm{ANa}$ $9005 \mathrm{CL}$ and ANa 9027.

Primeira contagem da emergência em areia (Plântulas viáveis- $7^{\circ}$ dia)

\begin{tabular}{lllll}
\hline & Lote 1 & Lote 2 & Lote 3 & Média \\
\hline ANa 8001 & $72,75 \mathrm{ABa}$ & $82,25 \mathrm{Ba}$ & $81,25 \mathrm{ABa}$ & $78,75 \mathrm{~B}$ \\
ANa 9005 CL & $80,75 \mathrm{Ba}$ & $85,25 \mathrm{Ba}$ & $85,75 \mathrm{Ba}$ & $83,91 \mathrm{~B}$ \\
ANa 9027 & $67,00 \mathrm{Aa}$ & $69,00 \mathrm{Aa}$ & $68,50 \mathrm{Aa}$ & $68,16 \mathrm{~A}$ \\
\hline \multicolumn{5}{c}{ Média } \\
\hline \multicolumn{5}{c}{ Germinação em areia (Plântulas viáveis-14 dia) } \\
\hline ANa 8001 & $90,25 \mathrm{Aa}$ & $91,50 \mathrm{ABa}$ & $91,75 \mathrm{Ba}$ & $91,16 \mathrm{~B}$ \\
ANa 9005 CL & $93,00 \mathrm{Aa}$ & $95,75 \mathrm{Ba}$ & $91,25 \mathrm{Ba}$ & $93,33 \mathrm{~B}$ \\
ANa 9027 & $88,25 \mathrm{Aa}$ & $86,00 \mathrm{Aa}$ & $81,75 \mathrm{Aa}$ & $85,33 \mathrm{~A}$ \\
\hline Média & $90,50 \mathrm{a}$ & $91,08 \mathrm{a}$ & $88,25 \mathrm{a}$ \\
\hline
\end{tabular}

Médias seguidas por uma mesma letra, maiúscula na coluna e minúscula na linha, não diferem estatisticamente (Tukey, p > 0,05).

Com relação aos lotes dentro de uma mesma cultivar não foram observadas diferenças estatísticas significativas. Esse resultado confere com o observado nos testes de primeira contagem da germinação e teste padrão de germinação, que caracterizam a cultivar $\mathrm{ANa} 9027$ com menor qualidade fisiológica em relação as cultivares ANa 9005 CL e ANa 8001 que apresentam maiores índices em todas as avaliações conduzidas.

Não são observadas diferenças significativas para as plântulas viáveis ao $14^{\circ}$ dia, dentro das cultivares. Embora, de forma geral observou-se para a média final das cultivares, a cultivar $\mathrm{ANa} 9027$ com menor índice de germinação, variando de $5,83 \%$ em relação a $\mathrm{ANa} 8001$ e em $8 \%$ para a ANa 9005 CL.

Nos resultados descritos pelos testes indiretos de tetrazólio, curva de embebição e condutividade elétrica verifica-se novamente que há coerência de resultados entre os testes realizados no presente trabalho, destacando a cultivar ANa 9005 CL e a cultivar $\mathrm{ANa} 9027$ como as de melhor e pior desempenho fisiológica, respectivamente, mas ambas dentro dos padrões comercializáveis da rizicultura. $\mathrm{Na}$ Tabela 4 estão apresentados os resultados para os índices de sementes viáveis contabilizadas no teste de tetrazólio.

Tabela 4. Teste de tetrazólio das cultivares de arroz ANa 8001, ANa 9005 CL e ANa 9027.

Table 4. Tetrazolium test of rice cultivars ANa 8001, ANa 9005 CL and $\mathrm{ANa} 9027$.

\begin{tabular}{lllll}
\hline \multicolumn{5}{c}{ Viabilidade } \\
\hline Lote 1 & Lote 2 & Lote 3 & Média \\
\hline ANa 8001 & $86,75 \mathrm{Ba}$ & $86,75 \mathrm{Aa}$ & $90,00 \mathrm{Bb}$ & $87,83 \mathrm{~B}$ \\
ANa 9005 CL & $92,75 \mathrm{Ca}$ & $94,75 \mathrm{Ba}$ & $94,00 \mathrm{Ca}$ & $93,83 \mathrm{C}$ \\
ANa 9027 & $82,25 \mathrm{Aab}$ & $83,50 \mathrm{Ab}$ & $80,50 \mathrm{Aa}$ & $82,08 \mathrm{~A}$ \\
\hline Média & $87,25 \mathrm{a}$ & $88,33 \mathrm{a}$ & $88,13 \mathrm{a}$ &
\end{tabular}

Médias seguidas por uma mesma letra, maiúscula na coluna e minúscula na linha, não diferem estatisticamente (Tukey, p > 0,05).

Novamente os resultados encontrados conferem com os resultados dos testes apresentados previamente, a cultivar $\mathrm{ANa} 9005 \mathrm{CL}$ apresentou os maiores índices de viabilidade entre as 3 cultivares. Para os 3 lotes estudados, a cultivar ANa 
8001 apresentou índices de vigor intermediários, enquanto a cultivar $\mathrm{ANa} 9027$ apresentou os menores índices de sementes viáveis.

Comparando-se os lotes de uma mesma cultivar, observamos para a cultivar ANa 8001 o lote 3 com maior índice de viabilidade. Para a cultivar ANa 9005 CL não houve diferenciação entre os lotes e para a cultivar $\mathrm{ANa} 9027$ o lote 3 apresenta índices de viabilidade menores que os demais.

Na curva de embebição (Figura 1), nota-se que o processo de hidratação das sementes segue um padrão trifásico, esse padrão de hidratação foi observado para as 3 cultivares estudadas, com uma curva ajustada com coeficiente de determinação de no mínimo $98 \%$ ao modelo estatístico polinomial de terceiro grau.

Observou-se na Figura 1a, que houve rápida absorção de água nas 12 primeiras horas de hidratação, sendo em média de $0,37 \mathrm{~g}$ de água para a cultivar $\mathrm{ANa} 8001,0,38 \mathrm{~g}$ para a cultivar ANa $9005 \mathrm{CL}$ e $0,36 \mathrm{~g}$ para a cultivar $\mathrm{ANa} 9027$. O que possibilitou um aumento médio de umidade de 15,83\% para a cultivar $\mathrm{ANa} 8001,15,57 \%$ para a cultivar $\mathrm{ANa} 9005$ CL e 14,38\% para a cultivar ANa 9027 (Figura 1b).

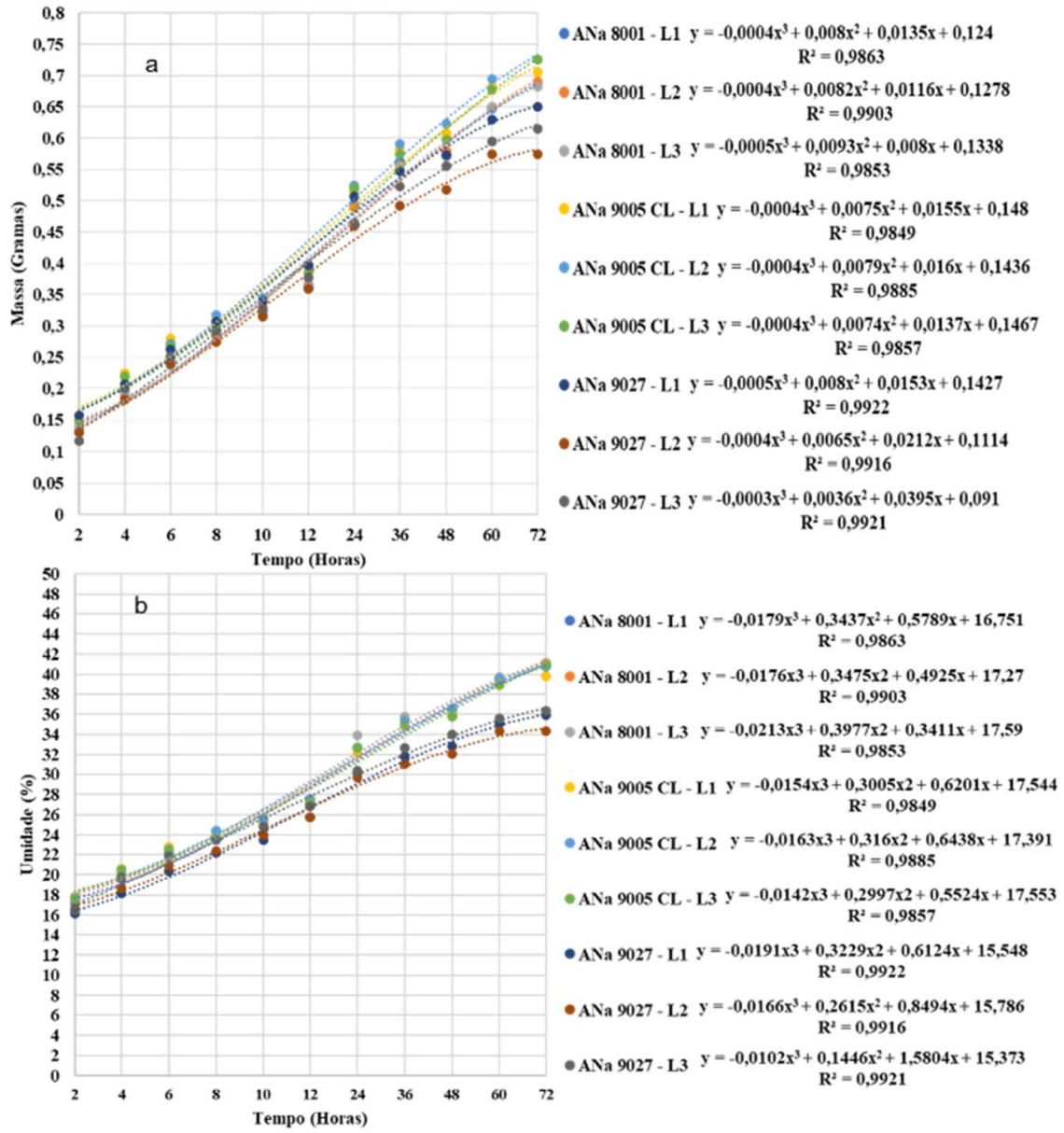

Figura 1. Valores observados e estimados do ganho de massa de água (a) e umidade (b) em relação ao tempo de embebição ao longo de 72 h, das sementes das cultivares de arroz ANa 8001, ANa 9005 CL e ANa 9027.

Figure 1. Observed and estimated values of water mass gain (a) and humidity (b) in relation to the soaking time over $72 \mathrm{~h}$, of the seeds of rice cultivars $\mathrm{ANa}$ 8001, $\mathrm{ANa} 9005 \mathrm{CL}$ and $\mathrm{ANa} 9027$.

Houve uma diminuição na absorção de água, 5,47\% para a cultivar ANa 8001, 5,25\% para a cultivar ANa 9005 CL e $3,97 \%$ para a cultivar $\mathrm{ANa} 9027$ nas $12 \mathrm{~h}$ seguintes.

Em relação a condutividade elétrica, as 3 cultivares avaliadas tiveram o mesmo padrão de liberação de lixiviados tanto para o teste conduzido no escuro quanto para as amostras mantidas sob iluminação durante $8 \mathrm{~h}$, resultados que podem ser observados na Figura 2.

Pode ser constatada a liberação de uma quantidade maior de lixiviados nas amostras privadas de luminosidade (SF) (Figura 2b). Considerando a média geral por cultivar, para as cultivares $\mathrm{ANa} 8001$ e $\mathrm{ANa} 9005 \mathrm{CL}$ não foram observadas diferenças significativas, porém, fica evidente a diferença entre a cultivar $\mathrm{ANa} 9027$ e as demais.

Essa diferença já é visível para o período de imersão de 4 h, aonde a cultivar $\mathrm{ANa} 9027$ apresentava leitura de condutividade por volta de $24 \mu \mathrm{S} \mathrm{cm}^{-1} \mathrm{~g}^{-1}$, enquanto as cultivares $\mathrm{ANa} 8001$ e ANa 9005 CL ambas expressavam valores em torno de $12 \mu \mathrm{Scm}^{-1} \mathrm{~g}^{-1}$. Essa tendência de distanciamento foi observada até o final do período de imersão considerado de $48 \mathrm{~h}$ e para as duas condições de luminosidade.

Para a cultivar $\mathrm{ANa}$ 8001, quando consideramos as avaliações anteriores, mesmo que com diferenças não significativas destacam-se os lotes 1 e 3 com menor e maior qualidade, respectivamente, nas duas condições de estudo avaliadas. Essa mesma tendência foi observada nas leituras de condutividade elétrica (Figura 3) conduzidos com fotoperíodo (Figura 3a), maiores valores foram lidos para o lote 1 indicando pior qualidade fisiológica do mesmo.

Para a cultivar ANa 9005 CL, com fotoperíodo (Figura 4a) e sem fotoperíodo (Figura 4b), observou-se diferenças 
pequenas entre os lotes, destacando-se o lote 3 com maiores valores de condutividade elétrica, já com 4 h de embebição, o que comprova os resultados observados nos testes anteriormente realizados, aonde o lote 3 da cultivar $\mathrm{ANa}$ 9005 CL apresentou qualidade fisiológica abaixo dos demais.

Para a cultivar ANa 9027 (Figura 5a - com fotoperíodo e $5 b$ - sem fotoperíodo), observou-se que não houve diferença expressiva entre as curvas de condutividade elétrica de cada lote, além disso, o lote 3 foi o que apresentou menor desempenho fisiológico nos testes anteriores, mesmo essa diferença não podendo ser considerada significativa, com curva de condutividade elétrica com valores mais baixos que os demais.
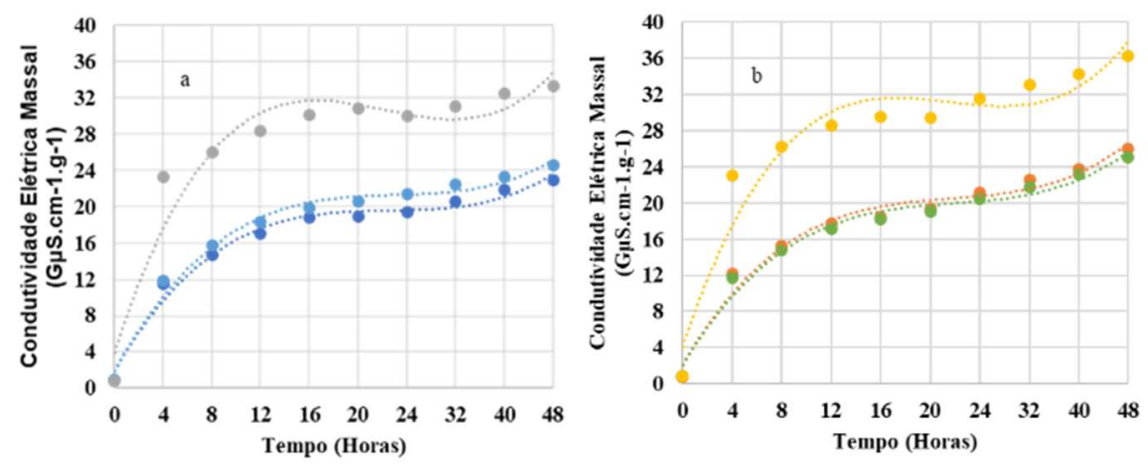

-ANa 8001 - CF $y=0,0972 x^{3}-1,9292 x^{2}+12,846 x-9,1401$ $\mathbf{R}^{2}=0,9825$

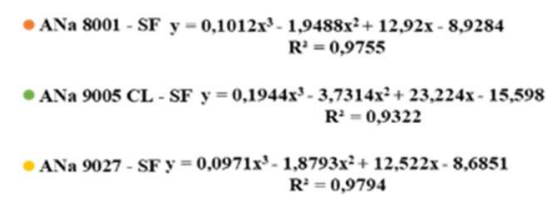

Figura 2. Valores observados e estimados da condutividade elétrica de sementes das cultivares de arroz ANa 8001, ANa 9005 CL e ANa 9027, ao longo de $48 \mathrm{~h}$ de embebição, com fotoperíodo (a) e sem fotoperíodo (b).

Figure 2. Observed and estimated values of the electrical conductivity of seeds of rice cultivars ANa 8001, ANa 9005 CL and ANa 9027 , over $48 \mathrm{~h}$ of soaking, with photoperiod (CF) and without photoperiod (SF).
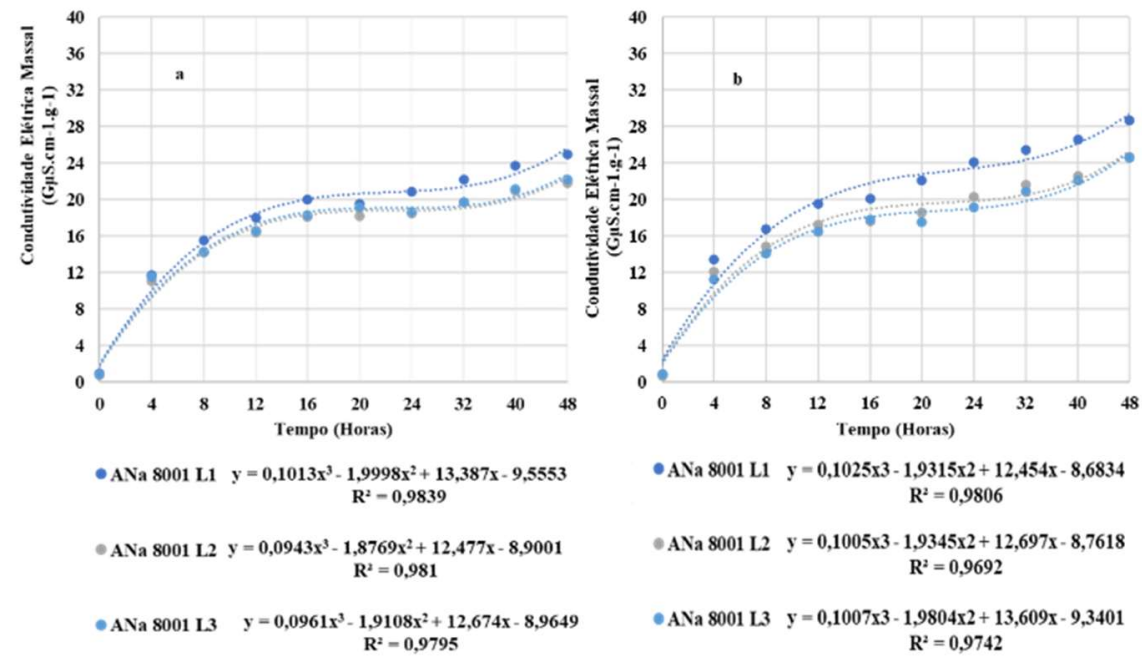

Figura 3. Valores observados e estimados da condutividade elétrica de sementes da cultivar de arroz ANa 8001 ao longo de 48 horas de embebição, com fotoperíodo (a) e sem fotoperíodo (b).

Figure 3. Observed and estimated values of electrical conductivity of seeds of rice cultivar ANa 8001 over 48 hours of soaking, with photoperiod (a) and without photoperiod (b).

\section{DISCUSSÃO}

Para o teste de condutividade elétrica, os valores de umidade estão de acordo com os referenciados por AOSA (1983), que salienta a influência significativa nos resultados da condutividade elétrica de sementes com umidade inferior a $10,0 \%$ ou superior a $17,0 \%$, a recomendação é que a umidade deve se situar entre 11,0 e $17,0 \%$.

Teores de água das sementes muito baixos elevam os valores de condutividade elétrica, já valores mais altos reduzem a saída de eletrólitos, diminuindo os valores de condutividade elétrica (BARBOSA et al, 2012). Marcos Filho (2015) também ressaltou a importância da uniformidade da umidade entre os lotes de sementes para a padronização das avaliações e obtenção de resultados consistentes.

Pelos resultados dos testes diretos de germinação e vigor, teste padrão de germinação e primeira contagem e teste de emergência em areia, verifica-se uma consonância nos resultados. Apenas sementes com alto vigor conseguem emergir e dar origem a uma plântula normal forte depois de 7 dias da semeadura, tendo assim uma emergência rápida, uniforme e com plântulas perfeitas, com maior velocidade de emergência e de desenvolvimento (FRANÇA-NETO, 2010), o que garante uma lavoura com maior desempenho e 
consequentemente melhores índices de produtividade (a lavoura terá menores problemas com incidência de plantas daninhas, menor necessidade de herbicidas, dentre outros fatores).

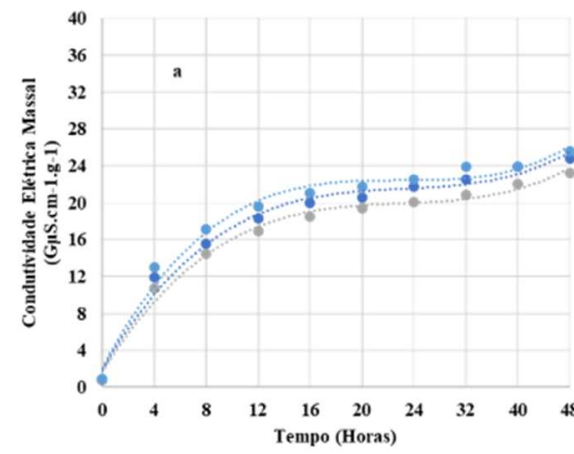

-ANa 9005 CL L1 $y=0,0932 \times 3-1,8961 x 2+13,13 x-9,3884$ $R^{2}=0.9846$

-ANa 9005 CL L2 y $=0,0883 \times 3-1,7906 \times 2+12,352 x-9,0028$
\[ R^{2}-0,9891 \]

-ANa 9005 CL L3 $y=0,107 x 3-2,1649 \times 2+14,613 x-10,462$

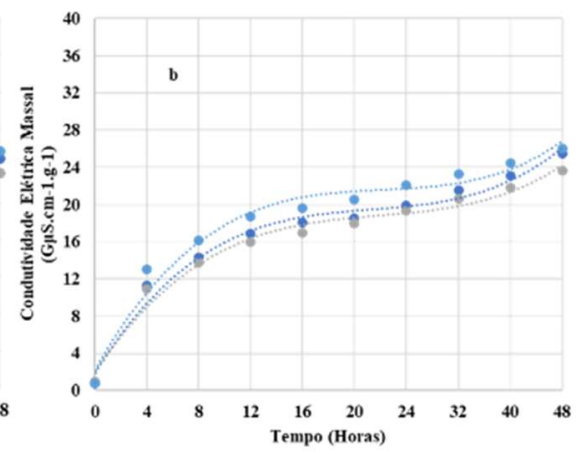

-ANa 9005 CL L1 y-0,1009x3 - 1,9142x2+12,55x-8,8708 $\mathbf{R}^{2}-0,9837$

- ANa 9005 CL L2 y $=0,0861 \times 3-1,6736 x 2+11,31 x-7,6386$ $\mathbf{R}^{2}=0,9803$

Figura 4. Valores observados e estimados da condutividade elétrica de sementes da cultivar de arroz ANa 9005 CL ao longo de 48 horas de embebição, com fotoperíodo (a) e sem fotoperíodo (b).

Figure 4. Observed and estimated values of electrical conductivity of seeds of rice cultivar ANa 9005 CL over 48 hours of soaking, with photoperiod (a) and without photoperiod (b).
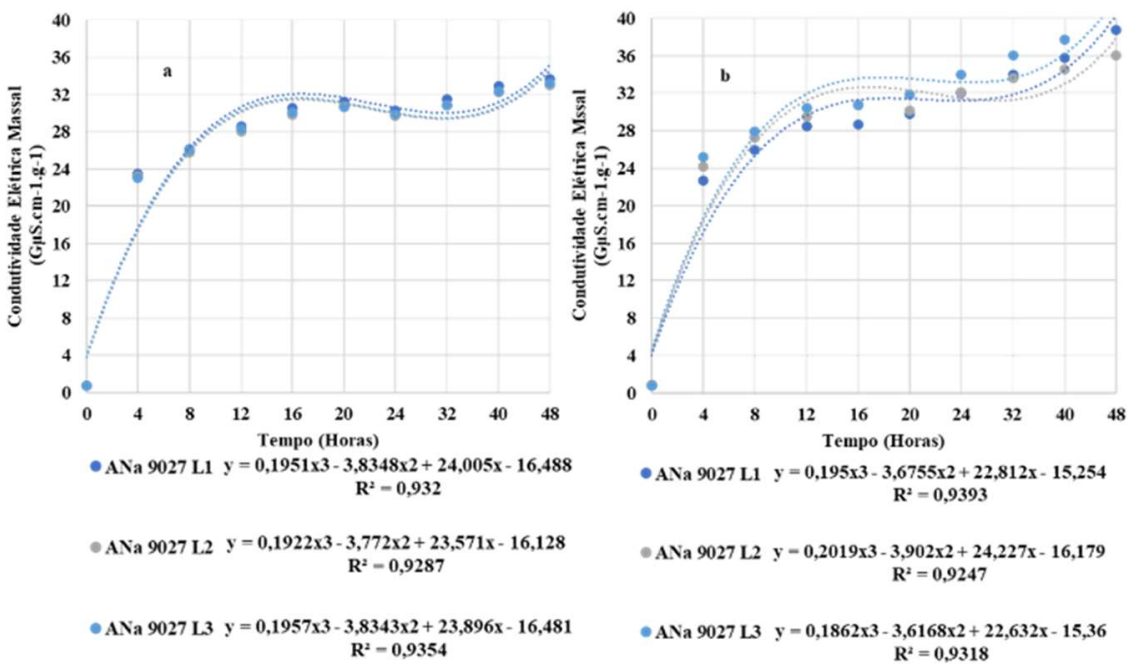

-ANa 9027 L1 $y=0,195 \times 3-3,6755 x 2+22,812 x-15,254$ $\mathrm{R}^{2}=0,9393$

-ANa 9027 L2 $y=0,2019 \times 3-3,902 \times 2+24,227 x-16,179$ $\mathrm{R}^{2}=0,9247$

- ANa 9027 L3 y $=0,1862 \times 3-3,6168 \times 2+22,632 x-15,36$

Figura 5. Valores observados e estimados da condutividade elétrica de sementes da cultivar de arroz ANa 9027 ao longo de 48 horas de embebição, com fotoperíodo (a) e sem fotoperíodo (b).

Figure 5. Observed and estimated values of electrical conductivity of seeds of rice cultivar ANa 9027 over 48 hours of soaking, with photoperiod (a) and without photoperiod (b).

Desta forma a primeira contagem do teste de germinação é um indicativo do vigor e é apontado como eficiente para avaliar o vigor de sementes (AOSA, 1983), é conduzido em condições totalmente favoráveis podendo beneficiar lotes de vigor médio a alto, isso ocorre pelo fato de que o vigor das sementes integra fatores que vão além da simples viabilidade.

No presente estudo não foi possível estratificar de forma significativa os lotes dentro da mesma cultivar, devido os valores de vigor serem muito próximos, mesmo havendo diferença numérica para alguns lotes.

O teste foi eficiente em estratificar diferenças acima de 5,61 pontos, o que ocorreu nas médias finais por cultivares, o mesmo foi constatado por Wrasse (2009), que também utilizando o teste da primeira contagem da germinação para avaliar a qualidade das sementes de arroz, verificou que esse teste foi pouco sensível para diferenciar os lotes em diferentes níveis de vigor.
As plântulas normais fortes e/ou apenas normais, contabilizadas aos 14 dias de semeadura nos fornece o índice de germinação, ou seja, são plântulas que independentemente de seu porte, tem a capacidade de dar origem a uma planta normal, porém que demoram um tempo maior para se estabelecerem no campo.

A tendência apresentada no teste de germinação é igual ao verificado para o teste de primeira contagem, ou seja, a cultivar ANa $9005 \mathrm{CL}$ apresenta índices fisiológicos superiores aos da cultivar $\mathrm{ANa}$ 8001, tendo a cultivar $\mathrm{ANa}$ 9027 o pior índice de germinação e consequentemente o pior desempenho fisiológico. Essa tendência se repetiu para os 3 lotes avaliados.

O teste foi satisfatório na estratificação das cultivares em relação à qualidade fisiológica. Essa diferença pode ser resultado de vários fatores, tanto externos quanto intrínsecos a cada cultivar. 
Os fatores externos foram semelhantes para as 3 cultivares. O período de plantio e colheita das 3 cultivares ocorreram com aproximadamente 1 mês de diferença em campos de semente localizados próximos, na mesma propriedade, podendo haver variabilidade de solo e de condições climáticas.

A cultivar $\mathrm{ANa} 8001$ apresentou ciclo mais curto em 3 dias em comparação as cultivares ANa 9005 CL e ANa 9027, procedimento de colheita, secagem e beneficiamento padronizado e armazenamento inicial em armazém convencional e posteriormente em câmara fria para as 3 cultivares.

Para confirmar a avaliação de plântulas em caso de dúvidas, quando apresentarem sintomas fitotóxicos, por exemplo, ou excesso de infecções patológicas, a areia é o substrato usado alternativamente.

Para a emergência em areia, as considerações são semelhantes as considerações para o teste de primeira contagem da germinação e teste padrão de germinação, são consideradas as plântulas emergidas e normais ao $7^{\circ}$ dia da semeadura, entende-se que se está avaliando o vigor (BRASIL, 2009), e posteriormente a contagem é refeita ao $14^{\circ}$ dia, contabilizando então o índice de germinação final.

Algumas diferenças foram observadas no teste de primeira contagem da emergência em areia que não se repetiu para a germinação em areia, ou seja, nem sempre a maior ou menor quantidade de plântulas normais no sétimo dia determina a maior germinação final, pois o vigor individual das sementes pode manifestar-se de modo variável, nos lotes de qualidade baixa ou intermediária.

Ademais, o período de duração do teste de germinação, favorece a expressão do potencial máximo, mesmo para aquelas sementes que tenham menor vigor.

Desta forma lotes e cultivares com diferença significativa na primeira contagem, não apresentaram essa diferença na contagem final. De forma geral, para as duas avaliações a cultivar ANa 9005 CL se destacou como a de melhor e a cultivar ANa 9027 como a de pior qualidade fisiológica.

Quando avaliamos os resultados dos testes indiretos, como o teste de tetrazólio, curva de embebição e condutividade elétrica massal, verificamos a mesma conformidade nos resultados, observada nos testes anteriores. O teste de tetrazólio para as sementes de arroz é capaz de estimar para determinado lote, de forma indireta os índices de viabilidade das sementes.

De maneira geral o teste de tetrazólio permiti a estimativa rápida da viabilidade das sementes, conforme afirmado por Carvalho et al. (2017), além de permitir a identificação das estruturas essenciais das sementes (ELIAS, 2012; FRANÇANETO; KRZYZANOWSKI, 2019), com destaque para o embrião (Figura 6), formado pelo eixo central (coleóptilo, plúmula, raízes seminais, radícula, coleorriza) e pelo escutelo.

Possibilita também estimar a viabilidade das sementes dormentes e não dormentes, o que permite verificar se as sementes estão mortas ou apenas dormentes (CARVALHO et al. 2017), sementes de algumas espécies, especialmente o arroz, apresentam dormência (STINGHEN, 2015), o que resulta em possíveis erros na estimativa de germinação.

No presente estudo os resultados do teste de tetrazólio estão de acordo com os resultados dos testes de germinação apresentados previamente, confirmando os resultados já encontrados e indicando o baixo índice de sementes dormentes.

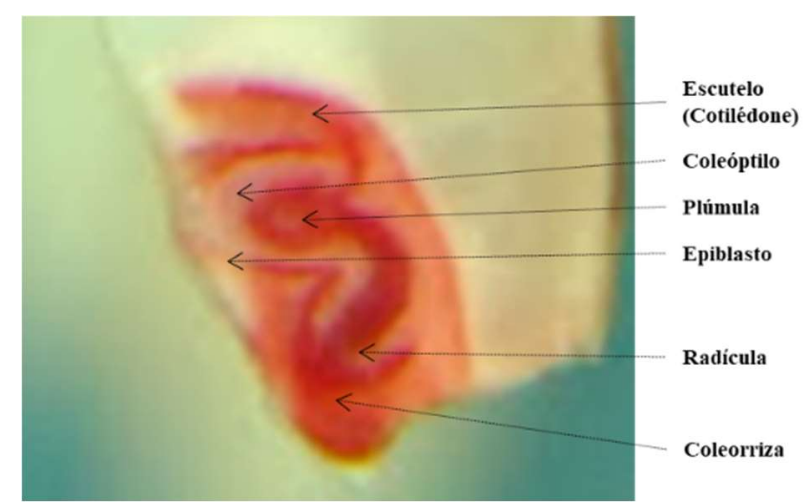

Figura 6. Morfologia da semente de arroz (Oriqa sativa), por meio do corte longitudinal destacando-se o embrião (Fonte: o autor).

Figure 6. Morphology of the rice seed (Oriza sativa), by means of the longitudinal section, highlighting the embryo (Source: the author).

Para a curva de embebição, o processo de hidratação das sementes segue um padrão trifásico, na primeira fase a absorção ocorre de forma rápida, devido à diferença do potencial matricial, como um dos componentes do potencial hídrico entre a semente e o substrato, na segunda fase a semente absorve água muito lentamente, reativando o metabolismo respiratório, e na terceira fase ocorre a retomada do crescimento do embrião, pelo aparecimento das estruturas morfológicas.

Esse padrão de hidratação foi observado para as 3 cultivares estudadas, o que foi reafirmado pela curva ajustada com coeficiente de determinação de no mínimo 98\% ao modelo estatístico polinomial de terceiro grau.

A tendência observada foi similar às fases da curva padrão descrito por Bewley et al., (2013). Houve rápida absorção de água nas 12 primeiras horas de hidratação e uma diminuição na absorção de água, nas $12 \mathrm{~h}$ seguintes. A redução drástica na velocidade de absorção de água é caracterizada como fase II que é marcada pela reativação do metabolismo, com aumento da difusão de solutos para regiões marcantes do metabolismo, região embrionária.

Após 36 h na cultivares ANa 8001 e ANa 9005 CL e após $48 \mathrm{~h}$ a cultivar ANa 9027, observou-se o início da ruptura da casca (Pálea e Lema) e o desenvolvimento da raiz primária, o que definiu o início da fase III, alcançada apenas por sementes vivas e não dormentes. Após o transcurso de $60 \mathrm{~h}$ a raiz primária das três cultivares já se encontrava visível e após esse período ocorreu o surgimento da parte aérea, sendo a variação de massa não mais considerada como ganho de umidade devido ao desenvolvimento visível das partes morfológicas das plântulas.

A absorção de água pelas sementes é um fator que pode interferir na interpretação do teste de condutividade elétrica, por exemplo (MARCOS FILHO, 2015).

Pesquisas têm sido realizadas com o objetivo de associar a velocidade de hidratação da semente com a qualidade fisiológica, pois a velocidade de hidratação/absorção parece ser afetada pela qualidade das sementes, constituindo-se, assim, em um indicativo de qualidade (WRASSE, 2009).

As sementes da cultivar ANa 9027 apresentaram menor desempenho fisiológico nos testes de vigor, germinação e viabilidade conduzidos, apresentaram também, valores menores de absorção de água, desde o início do processo de embebição, o que se acentuou a partir do decorrer das 24 primeiras horas. 
Os dados observados no presente estudo reafirmam os dados observados por Bortolotto et al. (2008), que estudando sementes de arroz constatou que a curva de embebição mostrou padrão semelhante ao observado em vários testes anteriormente aplicados, ou seja, menor velocidade de hidratação e umidade para o lote que apresentou menor qualidade em comparação aos lotes que mostraram maior qualidade, sem diferirem entre si.

Essa mesma tendência foi observada por Wrasse (2009) estudando 3 cultivares de arroz, em que a curva de hidratação das cultivares mostrou diferença na absorção de água entre o lote de menor qualidade e os demais lotes, que foram os de maior vigor e maiores teores de água, verificando assim que para a cultura do arroz irrigado as sementes com menor qualidade fisiológica têm menor velocidade de hidratação do que sementes de maior qualidade.

Não houve diferença significativa entre os lotes de uma mesma cultivar. A diferença de qualidade fisiológica dos lotes expressa nos demais testes também foi não significativa $\mathrm{e}$ consequentemente a leitura dessa diferença foi dificultada, constatando que a curva de embebição responde aos fatores fisiológicos de qualidade, quando esses possuem diferenças marcantes.

Acredita-se que a água e o oxigênio que ultrapassam a barreira da casca são aproveitados pelo metabolismo mais eficiente das sementes vigorosas e que esse metabolismo exija quantidade cada vez maior de água, aumentando a velocidade de hidratação e dado teores de água mais elevados nas primeiras horas.

Assim sendo, é possível relacionar a velocidade de hidratação com a qualidade fisiológica das sementes de arroz, de modo que o lote de menor qualidade absorveu água mais lentamente e em menor quantidade do que lotes com maior qualidade fisiológica.

Constatou-se, portanto, que a qualidade fisiológica do arroz afetou a quantidade de água absorvida e alcançado pelas sementes durante a hidratação, sendo as sementes menos vigorosas aquelas de menor velocidade de hidratação e umidade, comparativamente às sementes de maior vigor, quando a diferença é significativa para os demais testes.

Sabe-se que o teste de condutividade elétrica se apresenta consistente para a determinação do vigor, como uma metodologia rápida e simples, como constatado por alguns pesquisadores (BARBIERI, 2011), porém, para sementes de arroz, não há uma metodologia padronizada que responda de forma eficiente.

Com relação a condução do teste de condutividade elétrica sob fotoperíodo ou não, a luz é um recurso ambiental crítico para o desenvolvimento dos vegetais, é considerada muito importante para a fisiologia das plantas e germinação de sementes (Fotoblastismo).

Quando as sementes apresentam sensibilidade à luz, dizse que são fotoblásticas positivas e quando a germinação não ocorre em presença da luz, apresentam fotoblastismo negativo, sendo a luz recurso ambiental essencial ao metabolismo vegetal.

Plantas como o arroz não apresentam qualquer sensibilidade à presença ou ausência da luz, com fotoblastismo neutro, ou seja, a germinação não é interferida pela ausência ou presença da luz.

Porém as plantas são seres vivos fotossintetizantes e, portanto, dependem da luz, visto que este é um processo de transformação de energia luminosa em energia química, que visa a nutrição orgânica e, portanto, pode influenciar na velocidade de germinação mesmo em sementes com fotoblástismo neutro.

Apesar da possibilidade de a luminosidade causar interferências nas leituras de condutividade elétrica, essa diferença não foi visualizada neste estudo, as 3 cultivares avaliadas tiveram o mesmo padrão de liberação de lixiviados tanto para o teste conduzido no escuro quanto para as amostras mantidas sob iluminação durante $8 \mathrm{~h}$.

Porém, pode ser constatada a liberação de uma quantidade maior de lixiviados nas amostras privadas de luminosidade.

A curva de condutividade elétrica segue o mesmo padrão trifásico da curva de embebição, podendo ser descrita satisfatoriamente com coeficiente de determinação mínimo de $93 \%$ por um modelo polinomial de terceira ordem.

Isso ocorre devido a rápida absorção de água pelas sementes no início do processo de hidratação acarretando uma rápida liberação de lixiviados nas primeiras 24 h, o que eleva os valores da condutividade elétrica nesse mesmo período. Após 24 h de imersão ocorre a redução da absorção de água, coincidindo com a fase II do processo de hidratação.

Consequentemente, a quantidade de lixiviados liberados por tempo de hidratação se reduz, acarretando um menor incremento nos valores das leituras da condutividade elétrica. A fase III do processo de embebição é percebida na curva de condutividade elétrica pela estabilização dos valores lidos com o passar do tempo da imersão.

Modelos semelhantes, com o mesmo padrão e curva de tendência foram encontrados por Bortolotto et al., (2008) e Wrasse (2009) em sementes de arroz.

Os resultados encontrados no teste de condutividade elétrica são inversamente proporcionais à qualidade fisiológica das sementes, pois quanto mais danificada é a membrana celular, maior é o extravasamento do conteúdo celular, com maior atenção para os solutos presentes no citosol que passam para o meio aquoso.

A partir desse pressuposto observou-se que o resultado do teste de condutividade elétrica está de acordo com o observado no conjunto de testes realizados, que destacaram a cultivar ANa 9027 como a de menor qualidade fisiológica.

Para as cultivares ANa 8001 e ANa 9005 CL não foram observadas diferenças significativas em relação a condutividade elétrica. Logo, foi possível a diferenciação entre a cultivar com pior desempenho fisiológico das demais, que por sua vez apresentam valores próximos de germinação, por exemplo.

Souza et al. (2005), estudando o teste de condutividade elétrica para sementes de arroz, verificaram que o mesmo conseguiu indicar apenas as cultivares que apresentaram alta e baixa porcentagem de germinação, pois apresentaram os menores e maiores valores, respectivamente. Para os lotes ou cultivares que apresentaram porcentagem de germinação próxima, não foi possível diferenciá-los através desse teste.

O mesmo ocorre para os lotes de uma mesma cultivar, não foi possível observar uma diferença significativa, não sendo possível a distinção entre lotes de melhor ou pior qualidade, isso se deve a semelhança de qualidade entre os lotes estudados de uma mesma cultivar. Apesar de apresentarem alguma diferença nos demais testes realizados, essa diferença na qualidade fisiológica, não é suficiente para expressar um valor de exsudados e, portanto, de condutividade elétrica considerável.

Porém, para a cultivar ANa 8001 e ANa 9005 CL observou-se uma diferenciação dos lotes em função dos 
diferentes níveis de vigor, mesmo essas diferenças sendo pequenas e não significativas estatisticamente e para a cultivar ANa 9027 isto não foi verificado.

Muitas vezes, as causas do insucesso do teste de condutividade elétrica têm sido atribuídas à influência do genótipo, associada a características do tegumento, o que ocasiona a liberação de lixiviados mais ou menos acentuadas.

Resultados semelhantes foram encontrados em trabalho conduzido com sementes de arroz por Barbieri (2011), demostrando que sementes de distintos genótipos apresentaram diferentes valores de condutividade elétrica da solução de imersão, mesmo essas diferenças não sendo constatadas pela germinação e vigor avaliados por outros testes. Portanto os genótipos também podem interferir nos resultados da condutividade elétrica.

De forma geral é possível identificar diferenças, mesmo que não significativas e em lotes que se destacam por sua melhor ou pior qualidade fisiológica. Crusciol et al. (2001), trabalhando com arroz de terras altas, conseguiram identificar, por meio do teste de condutividade elétrica lotes que possuíam germinação acima de $87 \%$, diferenciando-os daquele que apresentava porcentagem de germinação abaixo de $84 \%$. Em sementes de arroz observa-se que o teste foi eficiente na avaliação da qualidade fisiológica de sementes com alta germinação, opondo-se aos resultados encontrados neste estudo, onde o teste foi mais eficiente quando realizado em sementes com baixa germinação.

Essa informação condiz com o observado por Silva et al. (2013), para sementes de triticale, aonde o teste de condutividade elétrica foi sensível apenas para confirmação do lote de menor desempenho e não foi sensível na caracterização de diferenças significativas entre os lotes com desempenho fisiológico semelhante.

$O$ estabelecimento de lotes com maior ou menor desempenho fisiológico não propicia a estimativa do nível de vigor das sementes de todas as categorias - normais, anormais ou mortas. Muitas sementes que germinam podem ter a mesma condutividade elétrica das sementes das demais categorias não viáveis.

Com relação ao período de imersão das sementes, para as três cultivares, verificou-se um aumento progressivo das leituras com o aumento do número de horas, corroborando com os dados de Coelho et al., (2014) e Barbieri (2011).

Observou-se que, de maneira geral, o período de imersão de quatro a oito horas, estratificou as cultivares quanto ao potencial fisiológico, corroborando com os resultados encontrados por Barbieri (2011), também em sementes de arroz.
É possível verificar a possibilidade de redução do período de imersão das sementes em relação ao período de $24 \mathrm{~h}$, considerado padrão, para $8 \mathrm{~h}$, com a segura diferenciação entre sementes com potencial fisiológico dentro dos padrões recomendados, acima de $80 \%$, das abaixo desse padrão.

Resultados semelhantes foram encontrados por Costa et al. (2015), em sementes de arroz e Menezes et al. (2007), em sementes de aveia preta, constataram que o tempo de imersão para realização do teste de condutividade elétrica pode ser reduzido para oito horas, com eficiência dos resultados.

No entanto, quando consideramos a diferenciação dos lotes dentro de uma mesma cultivar, essa estratificação só foi considerada consistente, a partir do período de $12 \mathrm{~h}$ e $16 \mathrm{~h}$ de imersão para os testes conduzidos sem e com fotoperíodo, respectivamente.

De forma geral, verificou-se que para as cultivares $\mathrm{ANa}$ 8001, ANa 9005 CL e ANa 9027, os testes da qualidade fisiológica considerados corroboram um com o outro, dentro de seu nível de avaliação.

Em todos os testes são observadas para as cultivares a mesma atuação, ou seja, a cultivar ANa 9005 CL com melhor desempenho fisiológico e a cultivar $\mathrm{ANa} 9027$ com o pior desempenho fisiológico.

De forma geral observou-se que todos os testes fisiológicos de viabilidade, germinação e vigor estão condizentes entre si, sendo parâmetros confiáveis para a análise qualitativa dos lotes e das cultivares. Com essa informação podemos correlacionar os testes de qualidade fisiológica de sementes, já consagrados para a cultura do arroz com o teste de condutividade elétrica.

A pequena variação entre os resultados obtidos nos testes sugere, justamente, a necessidade de realização de um maior número possível de testes antes de classificar os lotes quanto ao potencial fisiológico, pois cada teste tem um princípio metodológico diferente e fornece informações complementares para a decisão a respeito do destino final de comercialização de cada lote de semente da cultura.

Mediu-se também a relação existente entre os testes através do coeficiente da correlação de Pearson, sendo os resultados apresentados na Tabela 5 .

Destaca-se na Tabela 5 a correlação negativa entre os testes de condutividade elétrica e os demais testes, fator que condiz com o princípio do teste, ou seja, o grau de organização das membranas e a quantidade de lixiviados na solução de imersão permitem relacionar de forma negativa os valores de condutividade elétrica com o vigor de sementes, em que maiores valores de condutividade indicam sementes pouco vigorosas e, menores valores, condizem a sementes de maior potencial fisiológico (ASSIS; DALASTRA, 2019).

Tabela 5. Coeficiente de correlação entre as médias dos testes de desempenho fisiológicos das sementes das cultivares de arroz ANa 8001 , ANa 9005 CL e ANa 9027.

\begin{tabular}{lccccccc}
\hline & $*$ CEM SF & CE MA & TPG PC & TPG G & TEA PC & TEA G & TT \\
\hline CEM CF & 0,91 & 0,53 & $-0,72$ & $-0,70$ & $-0,60$ & $-0,53$ & $-0,73$ \\
CEM SF & - & 0,58 & $-0,76$ & $-0,76$ & $-0,70$ & $-0,62$ & $-0,79$ \\
CE MA & - & - & 0,54 & 0,39 & 0,31 & 0,29 & 0,54 \\
TPG PC & - & - & - & 0,83 & 0,63 & 0,55 & 0,83 \\
TPG G & - & - & - & - & 0,65 & 0,57 & 0,92 \\
TEA PC & - & - & - & - & - & 0,55 & 0,66 \\
TEA G & - & - & - & - & - & - & 0,57 \\
\hline
\end{tabular}

*CEM SF (condutividade elétrica sem fotoperíodo), CEM CF (condutividade elétrica com fotoperíodo), CE MA (curva de embebição massa de água), TPG PC (teste padrão de germinação primeira contagem), TPG G (teste padrão de germinação), TEA PC (teste de emergência em areia primeira contagem), TEA G (teste de emergência em areia germinação) e TT (teste de tetrazólio). 
A correlação entre os testes de condutividade elétrica e os demais testes variou de $-0,53$, para o teste de emergência em areia considerando a germinação e a condutividade elétrica conduzida com fotoperíodo, a $-0,79$ para o teste de tetrazólio e a condutividade elétrica conduzida sem fotoperíodo, ou seja, há correlação negativa entre os testes.

Observa-se que o teste de condutividade elétrica conduzido sem fotoperíodo se correlaciona mais fortemente com os demais testes do que quando conduzido sob fotoperíodo, dando um indicativo de ser mais preciso, do ponto de vista metodológico.

Com relação a curva de embebição a maior correlação foi obtida na primeira contagem do teste de germinação e para o teste de tetrazólio, $54 \%$.

O teste de tetrazólio foi correlacionado na ordem de $83 \%$ com a primeira contagem do teste padrão de germinação, $92 \%$ com o teste padrão de germinação e $66 \%$ com o teste de emergência em areia primeira contagem. $O$ teste padrão de germinação se correlaciona $65 \%$ com o teste de emergência em areia primeira contagem.

Foram consideradas de maior importância somente as correlações que apresentaram valores iguais ou superiores a 0,6, pois de acordo com Markus (1973) são valores mínimos para aceitação da associação entre testes correlacionados.

\section{CONCLUSÕES}

O menor desempenho fisiológico nos testes diretos (vigor e de germinação) e nos indiretos (viabilidade) foi para as sementes da cultivar de arroz $\mathrm{ANa} 9027$.

Os genótipos de arroz caracterizaram-se pelo padrão trifásico da curva de liberação de lixiviados pelo teste de condutividade elétrica e absorção de água.

O teste de condutividade elétrica é consistente na determinação do vigor de sementes de distintos genótipos de arroz, principalmente no apontamento de lotes com baixo desempenho fisiológico.

$\mathrm{Na}$ condução do teste de condutividade elétrica é possível reduzir o período de imersão das sementes de arroz para $8 \mathrm{~h}$, na diferenciação do potencial fisiológico de sementes de diferentes genótipos com vigor acima de $80 \%$, das abaixo desse padrão.

$\mathrm{O}$ teste de condutividade elétrica conduzido sem fotoperíodo apresenta maior correlação com os demais testes, tornando-o mais representativo do ponto de vista metodológico.

\section{REFERÊNCIAS}

ABRASEM_Associação Brasileira de Sementes e Mudas. Anuário. Brasília. 2018. 130p.

AOSA_Association of Official Seed Analysts. Seed vigor testing handbook. East Lansing, AOSA, 1983. 88p.

ASSIS, A. A.; DALASTRA, I. M., Teste de condutividade elétrica para determinação de vigor de sementes de trigo. Revista Cultivando o Saber, Cascavel, v. 12, n. 4, p. 384-392, 2019.

BARBIERI, A. P. P. Determinação do potencial fisiológico de sementes de arroz baseado na integridade das membranas celulares. $81 \mathrm{p}$. Dissertação (Mestrado). UFSM, Santa Maria, 2011.

BARBOSA, R.; SILVA, C. B. da; MEDEIROS, M. A. de; CENTURION, M. A. P. da C.; VIEIRA, R. D. Condutividade elétrica em função do teor de água inicial de sementes de amendoim. Ciência Rural, Santa Maria, v. 42 , n. 1 , p. 45-51, 2012. DOI: https://doi.org/10.1590/S0103-84782012000100008

BEWLEY, J. D.; BRADFORD, K. J.; HILHORST, H. W. M.; NONOGAKI, H. Seeds: physiology of development, germination and dormancy. 3rd ed. New York: Springer, 2013. 392p.

BORTOLOTTO, R. P.; MENEZES, N. L.; GARCIA, D. C.; MATTIONI, N. M. Comportamento de hidratação e qualidade fisiológica das sementes de arroz. Bragantia, Campinas, v. 67, n. 4, p. 991-996, 2008. DOI: https://doi.org/10.1590/S0006-87052008000400023

BRASIL. Lei Federal $\mathbf{n}^{\circ} 10.711$ de 05 de agosto de 2003. Sistema Nacional de Sementes. Brasília, DF, 2003.

BRASIL. Ministério da Agricultura, Pecuária e Abastecimento, sistema BINAGRI-SISLEGIS, instrução normativa - IN 6/2009 de 18 de fevereiro de 2009.

CANTARELLI, L. D.; SCHUCH, L. O. B.; TAVARES, L. C.; RUFINO, C. A. Variability of soybean plants originated from seeds with different physiological quality levels. Acta Agronómica, v. 64, n. 3, p. 218-222, 2015. DOI: http:// dx.doi.org/10.15446/acag.v64n3.44511

CARVALHO, I. L.; MENEGHELLO, G. E.; TUNES, L. M.; JÁCOME, C. C.; SOARES, V. N. Methodological adjustments to the tetrazolium test in rice seeds. Journal of Seed Science, v. 39, n. 1, p. 41-49, 2017. DOI: https://doi.org/10.1590/2317-1545v39n1169643

COELHO, C. M. M.; POLLAK JÚNIOR, M. M.; SOUZA C. A.; PARIZOTO, C. Caracterização da qualidade fisiológica de sementes de arroz-crioulo da safra de 2010/2011. Científica, Jaboticabal, v. 42, n. 3, p. 278 284, 2014.

COSTA, R. A. B. S.; SCHMIDT, L.; ESTEVES, R. S.; ALVES, C. L.; PAGNUSSATT', F. A. Avaliação do Vigor em Sementes de Arroz por Condutividade Elétrica. In: V Simpósio de Bioquímica e Biotecnologia VSIMBBTEC. Anais... São Paulo: Blucher, 2015. p. 9598.

CRUSCIOL, C. A. C.; ARF, O.; ZUCARELI, C.; SÁ, M. E.; NAKAGAWA, J. Produção e qualidade fisiológica de sementes de arroz de terras altas em função da disponibilidade hídrica. Revista Brasileira de Sementes, Londrina, v. 23, n. 2, p. 287-293, 2001.

ELIAS, S. G; COPELAND, L. O; McDONALD, M. B; BAALBAKI, R. Z. Seed testing: principles and pratices, Michigan, 2012. 364p.

FRANÇA NETO, J. B.; KRZYZANOWSKI, F. C. Tetrazolium: an important test for physiological seed quality evaluation. Journal of Seed Science, v. 41, n. 3, p. 359-366, 2019. DOI: https://doi.org/10.1590/2317$1545 \mathrm{v} 41 \mathrm{n} 3223104$

FRANÇA NETO, J. B.; KRZYZANOWSKI, F. C. O vigor e o desempenho das sementes, In: ABRASEM. Associação Brasileira de Sementes e Mudas. Anuário, Brasília, p. 26-30, 2018.

FRANÇA NETO, J. B.; KRZYZANOWSKI, F. C.; HENNING, A. A. A importância do uso de sementes de soja de alta qualidade. Informativo ABRATES, Londrina, v. 20, n. 1-2, p. 37-38, 2010.

FRANDOLOSO, D. C. L. Avaliação do vigor de sementes de alface pelo teste de envelhecimento acelerado. 67f. Dissertação (Mestrado). UFPEL, Pelotas, 2016. 
MARQUES, E. R.; ARAÚJO, R. F.; ARAÚJO, E. F.; MARTINS FILHO, S.; SOARES, P. C.; MENDONÇA, E. M. Dormancy and enzymatic activity of rice cultivars seeds stored in different environments. Journal of Seed Science, v. 36, n. 4, p. 435-442, 2014. DOI: https://doi.org/10.1590/2317-1545v36n41031

MARCOS FILHO, J. Fisiologia de sementes de plantas cultivadas. Piracicaba: Fealq, 2015. 495p.

MARKUS, R. Elementos de estatística aplicada. Porto Alegre: DALC, 1973. 329p.

MENEZES, B. R. S.; MOREIRA, L. B.; PEREIRA, M. B.; LOPES, H. M.; COSTA, E. M.; CURTI, A. T. M. Características morfoagronômicas de dois genótipos de arroz vermelho em cultivo inundado. Revista Brasileira de Ciências Agrárias, Recife, v. 7, n. 3, p. 394-401, 2012.

MENEZES, N. L. de; GARCIA, D. C.; BAHRY, C. A.; MATTIONI, N. M. Teste de condutividade elétrica em sementes de aveia preta. Revista Brasileira de Sementes, Pelotas, v. 29, n. 2, p. 138-142, 2007. DOI: https://doi.org/10.1590/S0101-31222007000200019

MERTZ, L. M.; SEGALIN, S. R.; HUTH, C.; ROSA, T. D. Condutividade elétrica individual para a avaliação do potencial fisiológico de sementes de trigo. Informativo ABRATES, Santa Maria, v. 22, n. 1, p. 35-39, 2012.

RAJJOU, L.; DUVAL, M.; GALLARDO, K.; CATUSSE, J.; BALLY, J.; JOB, C.; JOB, D. Seed germination and vigor. Annual Review of Plant Biology, v. 63, n. 1, p. 507-533, 2012. DOI: https://doi.org/10.1146/annurev-arplant042811-105550

SILVA, B. A.; NOGUEIRA, J. L.; CARVALHO, T.C.; PANOBIANCO, M., Adequação da metodologia do teste de condutividade elétrica para sementes de triticale, Scientia Agraria Paranaensis, Marechal Cândido Rondon, v. 12, n. 4, p. 267-274, 2013.

SOUZA A. P. de; MOTA, L. L.; ZAMADEI, T.; MARTIN, C. C.; ALMEIDA, F. T. PAULINO, J. Classificação climática e balanço hídrico climatológico no estado de mato grosso, Nativa, Sinop, v. 1, n. 1, p. 34-43, 2013. DOI: $10.31413 /$ nativa.v1i1.1334

SOUZA, L. C. D.; CARVALHO, M. A. C.; BRAGA, L. F.; SOUSA, E M. P. Qualidade fisiológica de sementes de arroz da região de Matupá-MT. Revista de Ciências Agro-Ambientais, Alta Floresta, v. 3, n. 1, p. 110-116, 2005.

STINGHEN, J. C. Caracterização de cultivares de arroz irrigado quanto a dormência e tolerância ao frio na germinação. 2015. 135f. Tese (Doutorado em Produção Vegetal) - Universidade do Estado de Santa Catarina, Lages, 2015.

WRASSE, C. F. Testes de vigor para sementes de arroz e sua relação com o comportamento de hidratação de sementes e a emergência de plântulas. Revista Científica, Jaboticabal, v. 37, n. 2, p. 107-114, 2009. 